\title{
Boxer safety, and the relationship between the referee and the ringside physician
}

\author{
N K Sethi, MD, MBBS, FAAN \\ Department of Neurology, New York Presbyterian Hospital, Weill Cornell Medical Center, New York, USA
}

Corresponding author: N K Sethi (sethinitinmd@hotmail.com)

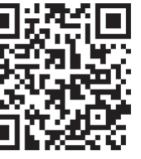

Both the referee and the ringside physician are entrusted with the safety of the boxer in the ring. The Uniform Boxing Rules (approved August 25, 2001, Amended August 2, 2002, Amended July 3, 2008) recognise the referee as the sole arbiter of a bout and the only individual authorised to stop a contest. Unified rules of mixed martial arts (MMA) and some boxing commissions recognise both the referee and the ringside physician as arbiters of a fight, and the only individuals authorised to enter the fight area at any time during competition and stop a fight when the combatant's safety is compromised. Irrespective of who stops the fight, the stoppage should be timely and fair to the combatants and their corners; a premature stoppage is unfair to the boxers, their corners, the promoter and the public, while a fight stopped too late risks serious injury and even death of the boxer. ${ }^{[1]}$

Stoppage from inside the ring by the referee is accepted by the boxer, his corner staff and the public (present in the arena and the wider television audience) more readily than stoppage from outside the ring by the ringside physician. Ringside physicians usually have a lower threshold for stopping a contest compared with the referee. Lack of knowledge of a boxer's punch-taking ability and fear of litigation may lead to premature stoppage of a fight by the ringside physician. Ideally, everyone would like the bout to be stopped before a life-threatening or career-ending injury occurs. The keyword here is before not after. However, most of the time this is not possible, so a more realistic goal should be timely identification of a serious injury in the ring and timely stoppage of a fight. For that to occur, the referee should be aware of the signs and symptoms of serious injuries. Since a referee's medical knowledge is limited, he and the ringside doctor need to act as a team.

The cause of sudden death in the ring is either cardiac or neurological. Cardiac causes are commonly identified by the ringside physician prior to the boxer entering the ring, during the course of the prefight medical check-up, when an electrocardiogram is reviewed and, if needed, an echocardiogram is requested. Neurological injuries in the ring are more difficult to determine clinically. Epidural haematomas and second-impact syndrome may lead to a walking, talking but dying boxer. Referees should be skilled in recognising concussions in the ring, especially of the more subtle grades 1 and 2 when the boxer is 'out on his feet', unable to defend himself, looks dazed, staggers around the ring or rests on the rope but does not experience loss of consciousness, is confused, does not remember the round, walks to the wrong corner after the bell or hits out at the referee. The referee should take into consideration the biomechanics of the punch thrown, the rotational and linear acceleration suffered by the skull and the impact deceleration before deciding to let the fight go on ${ }^{[2]}$ The modified Maddocks et al. ${ }^{[3]}$ questions can be quickly and easily administered in the ring by the referee to assess for concussion by asking the boxer questions such as: At what venue are you today? Which round is it now? Who are you fighting? How many rounds is the fight? If the boxer answers incorrectly, it is best to bring this to the attention of the ringside doctor in between the rounds. The boxer can then be further assessed to determine whether he can safely continue. After a boxer gets up from a knock-out, instead of making the boxer walk straight to him, the referee should ask him to take a few steps forward and then a step to the side to better assess his balance.

Ideally, a fight should be stopped by the referee after consulting with the ringside physician, after taking into account not just the most recent round but the previous rounds too, as well as the boxer's and his corner's body language. Good and constant communication between referee and ringside physician is the key. They should talk in between the rounds and share their assessment of the boxer with each other, supplementing each other's knowledge of medicine and boxing. The boxer's safety should always precede all other considerations.

\section{References}

1. Miele VJ, Bailes JE. Objectifying when to halt a boxing match: A video analysis of fatalities. Neurosurgery 2007;60(2):307-316. [http://dx.doi.org/10.1227/01. NEU.0000249247.48299.5B]

2. Stemper BD, Pintar FA. Biomechanics of concussion. Prog Neurol Surg 2014;28:14-27. [http://dx.doi.org/10.1159/000358748]

3. Maddocks DL, Dicker GD, Saling MM. The assessment of orientation following concussion in athletes. Clin J Sport Med 1995;5(1):32-35.

S Afr J Sports Med 2015;27(1):3. DOI:10.7196/SAJSM.595 